\title{
Association between Organophosphate Pesticide Exposure and Insulin Resistance in Pesticide Sprayers and Nonfarmworkers
}

\author{
Mathuramat Seesen ${ }^{1, *}\left(\mathbb{D}\right.$, Roberto G. Lucchini ${ }^{2,3}{ }^{\oplus}$, Somkiat Siriruttanapruk ${ }^{4}$, \\ Ratana Sapbamrer ${ }^{1}\left(\mathbb{D}\right.$, Surat Hongsibsong ${ }^{5}$, Susan Woskie ${ }^{6}\left(\mathbb{D}\right.$ and Pornpimol Kongtip ${ }^{7,8}$ \\ 1 Department of Community Medicine, Faculty of Medicine, Chiang Mai University, \\ Chiang Mai 50200, Thailand; lekratana56@gmail.com \\ 2 School of Public Health, Florida International University, Miami, FL 33199, USA; rlucchin@fiu.edu \\ 3 Occupational Medicine, University of Brescia, 25121 Brescia, Italy \\ 4 Department of Disease Control, Ministry of Public Health, Nonthaburi 11000, Thailand; \\ sirirut.somkiat@gmail.com \\ 5 School of Health Science Research, Research Institute for Health Science, Chiang Mai University, \\ Chiang Mai 50200, Thailand; surat.hongsibsong@cmu.ac.th \\ 6 Department of Public Health, Zuckerberg College of Health Sciences, University of Massachusetts Lowell, \\ Lowell, MA 01854, USA; Susan_Woskie@uml.edu \\ 7 Department of Occupational Health and Safety, Faculty of Public Health, Mahidol University, \\ Bangkok 10400, Thailand; pornpimol.kon@mahidol.ac.th \\ 8 Center of Excellence on Environmental Health and Toxicology, Bangkok 10400, Thailand \\ * Correspondence: smathuramat@gmail.com
}

Received: 20 October 2020; Accepted: 30 October 2020; Published: 4 November 2020

check for updates

\begin{abstract}
Insulin resistance is a risk factor for various diseases. Chronic organophosphate exposure has been reported to be a cause of insulin resistance in animal models. This cross-sectional study aimed to evaluate the association between organophosphate exposure and insulin resistance in pesticide sprayers and nonfarmworkers. Participants aged 40-60 years, consisting of 150 pesticide sprayers and 150 nonfarmworkers, were interviewed and assessed for their homeostatic model assessment of insulin resistance (HOMA-IR) level. Organophosphate (OP) exposure was measured in 37 sprayers and 46 nonfarmworkers by first morning urinary dialkyl phosphate (DAP) metabolites. The DAP metabolite levels were not different in either group except for diethylthiophosphate (DETP; $p=0.03$ ), which was higher in sprayers. No significant association was observed between DAP metabolite levels and HOMA-IR. Wearing a mask while handling pesticides was associated with lower dimethyl metabolites $(95 \% \mathrm{CI}=-11.10,-0.17)$. Work practices of reading pesticide labels $(95 \% \mathrm{CI}=-81.47,-14.99)$ and washing hands after mixing pesticide $(95 \% \mathrm{CI}=-39.97,-3.35)$ correlated with lower diethyl alkylphosphate level. Overall, we did not observe any association between OP exposure and insulin resistance in pesticide sprayers and the general population. However, personal protective equipment (PPE) utilization and work practice were associated with OP exposure level in sprayers.
\end{abstract}

Keywords: organophosphate; insulin resistance; dialkyl phosphate; pesticide sprayers; pesticide exposure; insecticides; metabolites

\section{Introduction}

Type 2 diabetes is one of the major global health problems and was reported by the World Health Organization (WHO) in 2018 as the seventh leading cause of death worldwide. Diabetes also leads to 
ischemic heart disease and stroke, which are reported as the first and second leading global cause of death, respectively [1]. In 2019, the world estimate for adult diabetic patients was 463 million, and the number is predicted to reach 700 million in 2045 [2]. In Thailand, the number of deaths from diabetes has increased dramatically during the past decade and reached 21.87 per 100,000 population in 2018 [3].

Insulin resistance is a significant underlying mechanism of metabolic syndrome [4] and type 2 diabetes [5]. Insulin resistance has also been reported to be a risk factor for cardiovascular disease [6,7] and cognitive impairment [8] and is associated with higher risk of endometrial [9], prostate [10], and colon cancer [11].

Genetic predisposition [12], obesity [13,14], and unhealthy lifestyle [15-18] represent other risk factors for insulin resistance. In addition, there is increasing evidence of chronic organophosphate (OP) exposure inducing insulin resistance in experimental animals [19-22].

As Thailand is an agricultural country and the world's leading rice exporter, pesticides are widely used, especially in upland agriculture [23]. Thailand's total pesticide use has reached the highest among the 10 Southeast Asian countries [24]. Most of the imported insecticides are OP chlorpyrifos. OP profenofos have also been reported among the top 10 imported insecticides in Thailand. In addition, the trend of OP imports in Thailand has increased steadily since 2011 [25].

Chiang Mai province in the northern region of Thailand is mostly covered by mountains and alluvial valleys. A study in 10 agricultural subdistricts in Chiang Mai found that 52\% of soil samples were contaminated by pesticide, mostly chlorpyrifos. Moreover, OP metabolites were measured in the urine of farmworkers recruited from these areas [26]. At the same time, Chiang Mai province has the highest diabetic incidence in northern Thailand and is ranked fourth among the country's provinces [27].

Studies on the effect of OP on human glucose level and insulin resistance are limited, and the available ones did not measure OP exposure through biomarkers [28-30]. To the best of our knowledge, there is only one human study of OP exposure and insulin resistance [31]. However, the target exposure of the study was malathion, which is different from the OPs commonly used in our area. In addition, other pesticide exposure and factors affecting insulin resistance were not measured. Therefore, this study aimed to determine the association between OP exposure and insulin resistance among pesticide sprayers and nonfarmworkers.

\section{Materials and Methods}

\subsection{Study Design and Participants}

A cross-sectional study was conducted in Chiang Mai province, Thailand, between May and July 2019, which is the period when the most intensive insecticide application occurs in agricultural villages. A community partnership that included village health volunteers, village headmen, and farmworker leaders was set up. People meeting the study criteria were recruited by the partnership. Participants aged 40-60 years and consisting of 150 pesticide sprayers from four agricultural villages and 150 subjects with no involvement in agricultural activity from three nonagricultural villages were enrolled. The inclusion criteria for the sprayers were having been pesticide sprayers for at least one year and having sprayed OP pesticides. The exclusion criteria were diagnosis of diabetes or consumption of antidiabetic medication, end-stage renal disease, cirrhosis, or consumption of HIV protease inhibitor. In addition, participants that were initially selected but were observed to have fasting plasma glucose of $126 \mathrm{mg} / \mathrm{dL}$ and higher were excluded.

Participants were requested to sign the consent form after full explanation of the study aims and methodology. After at least $8 \mathrm{~h}$ of fasting, each participant was interviewed and provided a blood sample to measure fasting blood glucose (FBG) and insulin levels.

A subset of 37 pesticide sprayers who had sprayed OPs in that season and planned to spray OPs within a month after blood collection as well as 46 nonfarmworkers were selected by convenience sampling for the measurement of urinary dialkyl phosphate (DAP) metabolites and lipid panel. 
To collect single morning urine sample, each participant was provided with a urine container and instructed for first morning urine collection in the following morning after OP spraying. Blood and urine collection as well as interviews were conducted for both farmworkers and nonfarmworkers at village temples.

Several subjects were excluded from the enrollment group. This included four farmers that were not pesticide sprayers, a sprayer with a small blood sample, and three sprayers and seven nonsprayers who had high FBG levels. The final group to be analyzed consisted of 142 sprayers and 143 nonsprayers, including 36 sprayers and 42 nonsprayers to be analyzed for urinary DAP metabolites.

\subsection{Questionnaire}

The questionnaire consisted of questions on sociodemographic and health information, $24 \mathrm{~h}$ dietary recall, physical activity, fresh produce consumption behavior, household pesticide use, work practice, and trade name of pesticides used (for pesticide sprayers).

A chart providing pictures of OPs and other pesticide containers that are generally used throughout Thailand was used for the interviews. Pesticide sprayers were asked to indicate the pesticide they have used in agricultural activities, while both groups of participants were asked to indicate household pesticide use.

Participants were asked to select the frequency of each activity regarding fresh produce consumption behavior. Pesticide sprayers were asked about frequency of use of personal protective equipment (PPE), which are gloves, boots, long-sleeved shirt, goggles, mask, and hat, and frequency of performing each activity while mixing or spraying pesticides.

Data from $24 \mathrm{~h}$ dietary recall was used to calculated daily calories by a nutritionist using the specialized Thai software NutriFact, which belongs to the Research Institute for Health Science, Chiang Mai University.

Information on duration and frequency of occupational activities, daily duration of walking or bicycling to work, and leisure-time activity was gathered. Participants who had done at least $150 \mathrm{~min}$ per week of moderate-intensity aerobic activity or $75 \mathrm{~min}$ per week of vigorous aerobic activity were classified as adequate physical activity.

The questionnaire was tested through pilot interview and refined by the research team and our community partnership. The local research team was trained by experts from the Research Institute for Health Science, Chiang Mai University. Questionnaires were administered through a face-to face interview by trained interviewers and research assistants from the Department of Community Medicine, Faculty of Medicine, Chiang Mai University.

\subsection{Anthropometric Measurement}

Waist circumference was measured at the midpoint between the lower margin of the lowest rib and the top of the iliac crest. Weight was measured with participants wearing light clothes and without shoes using a digital weighing scale. Height was measured without shoes using a stadiometer. The body mass index (BMI) was calculated as body weight $(\mathrm{kg})$ divide by height squared $\left(\mathrm{m}^{2}\right)$. Overweight and obesity was defined as having a BMI of 25 to $<30$ and 30 and higher, respectively.

\subsection{Exposure Measurement}

First morning urine was collected and placed in zip-lock plastic bags, stored in cold boxes with dry ice, shipped to the laboratory at the Research Institute for Health Science, Chiang Mai University, and refrigerated at $-20^{\circ} \mathrm{C}$ until extraction within seven days and analyzed afterward.

The six urinary DAP metabolites of OP pesticides—dimethylphosphate (DMP), dimethylthiophosphate (DMTP), dimethyldithiophosphate (DMDTP), diethylphosphate (DEP), diethylthiophosphate (DETP), and diethyldithiophosphate (DEDTP)—were measured in urine samples using gas chromatography with a flame photometric detector (GC-FPD) according to the published method of Prapamontol et al. [32]. The measured DAP concentrations were adjusted by creatinine and converted 
from the unit $\mu \mathrm{g} / \mathrm{L}$ to $\mu \mathrm{g} / \mathrm{g}$ creatinine. Creatinine in urine was determined by Jaffe's colorimetric reaction. Limit of detection (LOD) of DMP, DMPT, DMDPT, DEP, DETP, and DEDTP were 2.5, 0.4, 0.2, $0.25,0.1$, and $0.2 \mu \mathrm{g} / \mathrm{L}$, respectively. Total DAP metabolites ( $\sum \mathrm{DAPs}$ ) was calculated by summing the six individual DAP metabolites. Dimethyl alkylphosphate (DMAP) level was calculated by summing DMP, DMPT, and DMDPT. Diethyl alkylphosphate (DEAP) level was calculated by summing DEP, DETP, and DEDTP. To calculate $\sum$ DAPs, DMAPs, and DEAPs, mass concentration of DAPs was converted to molar concentration. Undetectable DAP metabolites were substituted with LOD divided by the square root of 2 [33].

\subsection{Outcome Measurement}

Venipuncture was done after $8 \mathrm{~h}$ of fasting by nurses at village centers and transferred to laboratories at the Faculty of Associated Medical Sciences, Chiang Mai University, and the Maharaj Nakorn Chiang Mai Hospital for analysis. Abbott ARCHITECT c8000 analyzer was used to analyze plasma glucose, cholesterol, high-density lipoprotein (HDL) cholesterol, and triglyceride level by the hexokinase method, enzymatic method, accelerator selective detergent, and glycerol phosphate oxidase, respectively. Insulin level was evaluated by electrochemiluminescence immunoassay and Cobas e411. Insulin resistance was measured by homeostatic model assessment of insulin resistance (HOMA-IR), which was calculated with the following equation: HOMA-IR = (fasting glucose (mg/dL) $\times$ fasting insulin $(\mu \mathrm{IU} / \mathrm{mL})) / 405$ [34]. Low-density lipoprotein (LDL) cholesterol was calculated using the Friedewald equation [35].

\subsection{Statistical Analysis}

Chi-square test for categorical variables and $t$-test for continuous variables were used to examine the demographic characteristics of participants. DAP metabolite levels in both pesticide sprayers and nonfarmworkers were analyzed using the Mann-Whitney $U$ test. Agricultural product consumption behavior between pesticide sprayers and nonfarmworkers were compared using chi-square test. Multiple linear regression analysis was performed to examine the association between DAP metabolites and blood chemistry levels as well as DAP metabolites and agricultural work practice in farmworkers. $p$-value $<0.05$ was considered statistically significant.

\subsection{Ethical Consideration}

All participants gave their informed consent for inclusion before participating in the study. The research procedure was approved by the Research Ethics Committee, Faculty of Medicine, Chiang Mai University, Thailand (Certificate Ethical Clearance No. 090/2019, 29 April 2019)

\section{Results}

\subsection{Demographic Information, HOMA-IR, and Glucose Level of Pesticide Sprayers and Nonfarmworkers}

The characteristics of participants by occupational status are presented in Table 1. Overall, pesticide sprayers were significantly older $(p=0.03)$, had a higher proportion of male $(p=0.02)$, and had lower education $(p<0.01)$ compared to nonfarmworkers. In addition, the sprayer group showed higher cardiometabolic risk factors, which were family history of diabetes $(p<0.01)$, smoking $(p=0.03)$, and excessive calorie $(p<0.01)$ and carbohydrate $(p<0.01)$ intake. Moreover, they reported higher hours of organophosphate pesticide exposure $(p<0.01)$, while no nonfarmworker reported OP exposure. 
Table 1. Characteristics of participants according to occupational status.

\begin{tabular}{|c|c|c|c|}
\hline Variable & $\begin{array}{l}\text { Pesticide Sprayers } \\
\qquad(\mathrm{n}=142)\end{array}$ & $\begin{array}{l}\text { Nonfarmworkers } \\
\quad(n=143)\end{array}$ & $p$-Value \\
\hline Age $\left(\right.$ mean \pm SD) ${ }^{a}$ & $50.15 \pm 6.35$ & $51.71 \pm 5.80$ & $0.03 *$ \\
\hline \multicolumn{4}{|l|}{ Sex, $n(\%)^{\mathrm{b}}$} \\
\hline Male & $57(40.1)$ & $39(27.3)$ & \multirow[t]{2}{*}{$0.02 *$} \\
\hline Female & $85(66.3)$ & $104(72.7)$ & \\
\hline \multicolumn{4}{|l|}{ BMI, $n(\%)$ b } \\
\hline Normal & $52(36.6)$ & $44(30.8)$ & \multirow{3}{*}{0.32} \\
\hline Overweight & $33(23.2)$ & $29(20.3)$ & \\
\hline Obese & $57(40.1)$ & $70(49)$ & \\
\hline \multicolumn{4}{|l|}{ Educational level, $n(\%)^{\mathrm{b}}$} \\
\hline Less than primary school & $68(47.9)$ & $30(21.0)$ & \multirow{3}{*}{$<0.01 *$} \\
\hline Primary school & $34(23.9)$ & $49(34.3)$ & \\
\hline High school & $33(23.2)$ & $45(31.5)$ & \\
\hline High vocational and college & $7(4.9)$ & $19(13.3)$ & \\
\hline Family history of diabetes, $n(\%){ }^{b}$ & $107(75.4)$ & $85(59.4)$ & $<0.01 *$ \\
\hline Excessive alcohol consumption, $n(\%)$ & $32(22.5)$ & $27(18.9 \%)$ & 0.44 \\
\hline Current smoking, $n(\%)^{\mathrm{b}}$ & $25(38)$ & $13(9.1)$ & $0.03 *$ \\
\hline Adequate physical activity, $n(\%) \mathrm{b}$ & $127(89.4)$ & $120(83.9 \%)$ & 0.17 \\
\hline Excessive calorie intake, $n(\%) \mathrm{b}$ & $37(26.1)$ & $19(13.3)$ & $<0.01 *$ \\
\hline Excessive carbohydrate intake, $n(\%){ }^{b}$ & $79(55.6)$ & $38(26.6)$ & $<0.01 *$ \\
\hline Cumulative OP exposure (hours) (mean \pm SD) ${ }^{a}$ & $447.06 \pm 2919.69$ & $0 \pm 0$ & $<0.01 *$ \\
\hline HOMA-IR $\left(\right.$ mean \pm SD) ${ }^{a}$ & $1.48 \pm 1.27$ & $2.30 \pm 2.88$ & $<0.01 *$ \\
\hline Abnormal HOMA-IR, $n(\%)^{b}$ & $32(22.5)$ & $54(37.8)$ & $<0.01 *$ \\
\hline Fasting blood glucose $(\text { mean } \pm \mathrm{SD})^{a}$ & $86.17 \pm 12.21$ & $90.88 \pm 11.84$ & $<0.01 *$ \\
\hline Abnormal fasting blood glucose, $n(\%){ }^{\mathrm{b}}$ & $17(12)$ & $25(17.5)$ & 0.18 \\
\hline
\end{tabular}

${ }^{a}$ tested as $t$-test, ${ }^{b}$ tested as chi-square. OP: organophosphate; HOMA-IR: homeostatic model assessment of insulin resistance, ${ }^{*} p<0.05$.

\subsection{Assessment of DAP Metabolite Levels}

Table 2 illustrates urinary DAP metabolites in the two groups. There was no significant difference in the proportion of participants who had DAP metabolite levels above and below LOD. In addition, DAP levels of both groups were similar except for DETP, which was higher in pesticide sprayers $(p=0.03)$.

Table 2. DAP levels ( $\mu \mathrm{g} / \mathrm{g}$ creatinine) and detection frequency in pesticide sprayers and nonfarmworkers.

\begin{tabular}{|c|c|c|c|c|c|}
\hline $\begin{array}{c}\text { Metabolites } \\
\text { ( } \mu \mathrm{g} / \mathrm{g} \text { creatinine) }\end{array}$ & \multicolumn{2}{|c|}{ Pesticide Sprayers $(n=36)$} & \multicolumn{2}{|c|}{ Nonfarmworkers $(n=42)$} & $p$-Value \\
\hline DMTP & $0.30(0.10,3.92)$ & $5(13.9)$ & $0.36(0.10,5.72)$ & 7 (16.7) & 0.25 \\
\hline DMDTP & $0.13(0.05,0.77)$ & $1(2.8)$ & $0.15(0.05,0.56)$ & $0(0)$ & 0.20 \\
\hline DEDTP & $0.14(0.05,18.12)$ & $9(25)$ & $0.16(0.05,1.65)$ & $2(4.8)$ & 0.99 \\
\hline$\sum \mathrm{DAP}$ & $7.30(1.19,74.37)$ & $34(94.4)$ & $6.63(2.81,18.02)$ & 40 (95.2) & 0.69 \\
\hline
\end{tabular}

Dialkyl phosphate (DAP) metabolite levels were analyzed using the Mann-Whitney $U$ test. DMP: dimethylphosphate; DMTP: dimethylthiophosphate; DMDTP: dimethyldithiophosphate; DEP: diethylphosphate; DETP: diethylthiophosphate; DEDTP: diethyldithiophosphate; $\sum$ DAPs: total DAP metabolites, ${ }^{*} p<0.05$.

\subsection{Assessment of Agricultural Product Consumption Behavior}

Assessment of agricultural product consumption behavior is presented in Table 3. A higher proportion of pesticide sprayers reported always consuming organic vegetables $(p<0.01)$, fruits $(p<0.01)$, and rice $(p<0.01)$. Moreover, a greater percentage of sprayers reported that they always have food cooked by themselves or their family members. 
Table 3. Agricultural consumption behavior in pesticide sprayers and nonfarmworkers.

\begin{tabular}{|c|c|c|c|}
\hline Behavior & Pesticide Sprayers, $n(\%)$ & Nonfarmworkers, $n(\%)$ & $p$-Value \\
\hline \multicolumn{4}{|c|}{ Organic vegetable consumption } \\
\hline Always & $63(44.4)$ & $35(24.5)$ & \multirow{3}{*}{$<0.01 *$} \\
\hline Sometimes & $43(30.3)$ & $44(30.8)$ & \\
\hline Rarely & $36(25.4)$ & $64(44.8)$ & \\
\hline \multicolumn{4}{|c|}{ Organic fruit consumption } \\
\hline Always & $40(28.2)$ & $22(15.4)$ & \multirow{3}{*}{$<0.01$ * } \\
\hline Sometimes & $57(40.1)$ & $42(29.4)$ & \\
\hline Rarely & $45(31.7)$ & $79(55.2)$ & \\
\hline \multicolumn{4}{|c|}{ Organic rice consumption } \\
\hline Always & $38(26.8)$ & $20(14.0)$ & \multirow{3}{*}{$<0.01 *$} \\
\hline Sometimes & $34(23.9)$ & $26(18.2)$ & \\
\hline Rarely & $70(49.3)$ & $97(67.8)$ & \\
\hline \multicolumn{4}{|c|}{$\begin{array}{l}\text { Eat food cooked by themselves or their } \\
\text { family members }\end{array}$} \\
\hline Always & $134(94.4)$ & $106(74.1)$ & \multirow[t]{3}{*}{$<0.01$ * } \\
\hline Sometimes & $6(4.2)$ & $31(21.7)$ & \\
\hline Rarely & $2(1.4)$ & $6(4.2)$ & \\
\hline \multicolumn{4}{|c|}{ Wash vegetables and fruits before eating } \\
\hline Always & $136(95.8)$ & $134(93.7)$ & \multirow{3}{*}{0.19} \\
\hline Sometimes & $3(2.1)$ & $1(0.7)$ & \\
\hline Rarely & $3(2.1)$ & $8(5.6)$ & \\
\hline
\end{tabular}

\subsection{Factors Associated with HOMA-IR, Glucose, and Lipid Levels}

Factors associated with HOMA-IR, fasting plasma glucose, and lipid levels in sprayers and the general population are shown in Tables 4 and 5. HOMAR-IR had significant correlation with only waist circumference $(95 \% \mathrm{CI}=0.03,0.09)$. Participants who reported to have family history of diabetes showed lower glucose level $(95 \% \mathrm{CI}=-13.67,-1.87)$. For lipid panel, high amount of alcohol consumption correlated with high triglyceride $(95 \% \mathrm{CI}=0.03,0.12)$. Triglyceride level was also higher in subjects who had excessive calorie intake $(95 \% \mathrm{CI}=30.84,183.53)$. Furthermore, female tended to have higher HDL $(95 \% \mathrm{CI}=2.86,11.77)$. However, no significant correlation was observed between DAP and HOMAR-IR, glucose, triglyceride, LDL, and HDL cholesterol.

Table 4. Factors associated with HOMA-IR and fasting blood glucose in sprayers and the general population.

\begin{tabular}{ccccccc}
\hline & \multicolumn{3}{c}{ HOMA-IR } & \multicolumn{3}{c}{ Fasting Blood Glucose } \\
\hline & Beta & SE & $\mathbf{9 5 \%}$ CI & Beta & SE & $\mathbf{9 5 \% ~ C I ~}$ \\
\hline Age & 0.07 & 0.02 & $-0.03,0.05$ & 0.19 & 0.23 & $-0.10,0.84$ \\
Sex & -0.06 & 0.32 & $-0.08,0.47$ & -0.22 & 3.45 & $-12.52,1.28$ \\
Educational level & 0.10 & 0.14 & $-0.14,0.42$ & 0.15 & 1.50 & $-1.14,4.85$ \\
Family history of diabetes & -0.05 & 0.28 & $-0.69,0.42$ & -0.31 & 2.95 & $-13.67,-1.87$ * \\
Excessive calorie intake & 0.09 & 0.33 & $-0.37,0.98$ & 0.06 & 3.58 & $-5.27,9.04$ \\
Physical activity & 0.06 & 0.52 & $-0.75,1.34$ & -0.10 & 5.55 & $-15.51,6.68$ \\
Smoking status & 0.004 & 0.60 & $-1.18,1.22$ & -0.09 & 6.38 & $-17.21,8.27$ \\
Diuretic taking duration & 0.06 & 0.44 & $-0.65,1.12$ & -0.04 & 4.70 & $-10.98,7.81$ \\
Alcohol consumption & -0.14 & 0.00 & $-0.001,0.00$ & -0.05 & 0.002 & $-0.005,0.003$ \\
Waist circumference & 0.46 & 0.01 & $0.03,0.09 *$ & 0.11 & 0.15 & $-0.16,0.46$ \\
LDAP & -0.20 & 0.01 & $-0.05,0.001$ & 0.06 & 0.14 & $-0.20,0.37$ \\
\hline
\end{tabular}

* Statistical significance. 
Table 5. Factors associated with lipid levels in sprayers and the general population.

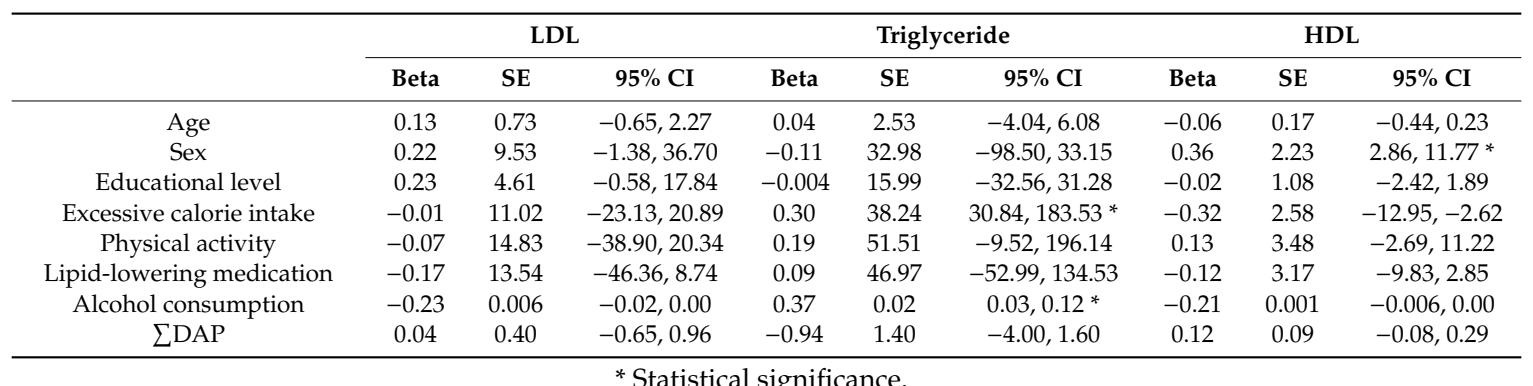

\subsection{Factors Associated with DAP Metabolites in Pesticide Sprayers}

Table 6 demonstrates factors associated with DAP metabolites in pesticide sprayers. For PPE utilization, gloves and boots were not analyzed as all sprayers reported to usually wear them. The association between higher frequency of wearing a mask while handling pesticide and DMAP level was observed $(95 \% \mathrm{CI}=-11.10,-0.17)$. Participants who reported lower frequency of reading pesticide labels $(95 \% \mathrm{CI}=-81.47,-14.99)$ and washing hands after mixing $(95 \% \mathrm{CI}=-39.97,-3.35)$ exhibited significant higher DEAP level.

Table 6. Factors associated with DAP metabolites in pesticide sprayers.

\begin{tabular}{|c|c|c|c|c|c|c|c|c|c|}
\hline \multirow{2}{*}{ Variables } & \multicolumn{3}{|c|}{ DAPs } & \multicolumn{3}{|c|}{ DMAPs } & \multicolumn{3}{|c|}{ DEAPs } \\
\hline & Beta & SE & $95 \%$ CI & Beta & SE & $95 \% \mathrm{CI}$ & Beta & SE & $95 \% \mathrm{CI}$ \\
\hline Age & -0.18 & 0.57 & $-1.61,0.96$ & 0.04 & 0.18 & $-0.38,0.43$ & -0.19 & 0.48 & $-1.43,0.73$ \\
\hline Sex & 0.04 & 6.00 & $-12.38,14.39$ & 0.57 & 1.90 & $-0.26,8.21$ & -0.12 & 5.04 & $-14.21,8.26$ \\
\hline Smoking status & 0.18 & 11.91 & $-19.26,33.81$ & 0.02 & 43.77 & $-8.10,8.70$ & 0.18 & 10.00 & $-15.31,29.26$ \\
\hline Duration of spraying pesticides & -0.30 & 0.46 & $-1.44,0.60$ & -0.41 & 0.14 & $-0.49,0.15$ & -0.17 & 0.38 & $-1.11,6.12$ \\
\hline Long-sleeved shirt & 0.18 & 16.91 & $-25.73,49.63$ & -0.38 & 5.35 & $-19.26,4.60$ & 0.30 & 14.20 & $-12.36,50.93$ \\
\hline Hat & 0.19 & 18.41 & $-28.26,53.75$ & -0.29 & 5.83 & $-18.56,7.42$ & 0.28 & 15.46 & $-16.12,52.78$ \\
\hline Eat during spraying & -0.03 & 12.29 & $-28.73,26.06$ & -0.26 & 3.89 & $-11.64,5.71$ & 0.04 & 10.33 & $-21.38,24.65$ \\
\hline Wash hands before eating & 0.25 & 8.81 & $-13.65,25.63$ & 0.25 & 2.79 & $-4.48,7.96$ & 0.18 & 7.40 & $-12.24,20.74$ \\
\hline Scratch body while spraying & 0.21 & 9.87 & $-15.81,28.19$ & -0.53 & 3.12 & $-11.47,2.46$ & 0.37 & 8.29 & $-7.79,29.17$ \\
\hline Read pesticide labels & -0.74 & 17.75 & $-88.12,8.98$ & -0.17 & 5.62 & $-12.85,12.21$ & -0.75 & 14.91 & $-81.47,-14.99$ * \\
\hline Mix with bare hands & 0.16 & 7.80 & $-12.23,22.54$ & 0.32 & 2.47 & $-2.58,8.43$ & 0.07 & 6.55 & $-12.37,16.83$ \\
\hline
\end{tabular}

\section{Discussion}

To the best of our knowledge, this is one of the first studies to determine the association between organophosphate exposure and insulin resistance in agricultural and nonagricultural workers. However, we could not demonstrate the correlation between organophosphate exposure and insulin resistance, fasting plasma glucose, triglyceride, HDL, or LDL cholesterol levels.

DAP metabolite levels of pesticide sprayers in this study were lower than previous studies, which could be from several possible causes. First, as different techniques were used to analyze DAP metabolites, LOD of our metabolites was higher than other studies. This was especially the case for DMP, which was $2.5 \mu \mathrm{g} / \mathrm{L}$ in our study compared to $0.26 \mu \mathrm{g} / \mathrm{L}$ in a study in the Netherlands [36]. This also led to the low percentage of DMP detection in our study. Another explanation could be that some farmworkers might not have followed the urine collecting instruction because of communication barriers as half of them were from the hill tribes.

DAP metabolites in the current study were also lower than that reported in a study of pesticide sprayers in Greece [37], which could be due to the lower proportion of PPE use. In the study, the percentage of sprayers who reported wearing gloves, hat, and mask was $35.5,52$, and $50 \%$, respectively, whereas it was $94.4,94.4$, and $88.9 \%$, respectively, in our study (data not shown). 
Similar to our result, the study pointed out that DETP level in sprayers was significantly higher than nonfarmworkers.

The average diethyl metabolite levels in our study were close to those in chili farmers in Thailand [38], where first morning urine was collected after spraying OPs. This could be the result of a similar DAP analyzing technique. Moreover, chlorpyrifos was commonly used among chili farmers in the study site.

Our study indicated that pesticide sprayers had significantly higher DETP metabolites than nonfarmworkers. This result is related to chlorpyrifos and ethion, the two most popular OPs used by pesticide sprayers, which can metabolize to DETP [39]. However, the levels of the other five metabolites were similar in both groups. This could be explained by the fact that nonfarmworkers had higher dietary OP pesticide exposure compared to pesticide sprayers as sprayers reported significantly higher organic produce consumption. This result correlates with several studies on the general population that have reported an association between DAP metabolites and higher fruit and vegetable intake $[36,40,41]$. Consumption of fresh produce contaminated with OP residues could be pointed as the main route of OP exposure in the general population, while organic diet consumption could reduce OP metabolites [42,43]. In addition, a study in Chiang Mai, Thailand, reported that the most common OP residue found in fresh produce was chlorpyrifos, which was detected in all kinds of fruit and vegetable samples [44].

Our study did not show an association between DAP metabolites and insulin resistance. This is consistent with a study on the US general population, which reported the lack of association between urinary DAP metabolites and HOMA-IR and plasma glucose [45]. This study result is in contrast with a previous research on pesticide applicators, which indicated the positive correlation between blood malathion concentration and HOMA-IR [32]. This could be explained by the questionable conclusion of this study that the waist circumference and BMI, which are mandatory factors of insulin resistance [46,47], of the farmer group were significantly higher than the control group. In addition, an association between lipid levels and OP exposure was not observed, whereas several studies in animal models have reported that OPs lead to an increase in LDL and triglyceride and a decrease in HDL [48,49]. Moreover, a study on humans showed the correlation between DMPT metabolite and higher HDL, lower LDL, and lower total cholesterol [45]. Thus, further human studies to examine the effect of OPs on lipid metabolism are needed.

Our study showed the inverse correlation between family history of diabetes and fasting plasma glucose level, which contradicts a previous study on the general population [50]. According to the Thai National Health Examination Survey, the proportion of undiagnosed diabetes was $51.2 \%$ for men and $41.3 \%$ for women [51]. Furthermore, some farmworkers in our study were of the hill tribe ethnic group, in which barriers to accessing healthcare services has been reported [52]. A survey on elderly Thai population pointed out that hill tribes had higher prevalence of diabetes compared to the general Thai population [53]. Therefore, the number of participants who reported family history of diabetes in our study might be lower than reality, especially in farmworkers. Another possible explanation could be greater awareness and risk perception in individuals who have familial risk of diabetes [54]; consequently, they are more likely to adopt healthy behaviors [55].

A reason behind the lack of association between OP exposure and chronic outcomes, namely, insulin resistance, glucose, and lipid levels, in our study could be the limitation of DAP metabolites. Although first morning urine has been pointed out as the best predictor of daily DAP metabolite concentration [56], various studies have reported that single urine analysis may not indicate chronic exposure $[57,58]$. Another reason could be the high exposure in the general population as over $90 \%$ of our nonfarmworkers had detectable DAP metabolites. Compared to studies among the general population in Israel and the US, our study showed higher diethyl alkyl metabolite levels [40,59]. Our participant enrollment process, in which the frequency of OP exposure in sprayers was not specified, could have affected the results. The frequency of pesticide spraying has been identified as being correlated with adverse health effects [60]. However, we analyzed the association between 
cumulative OP exposure and insulin resistance, but an association was not observed. In addition, there is evidence that exposure to carbamate pesticides alters glucose homeostasis in animals [61]. The current study did not assess carbamate levels because the sprayers reported that the most recent carbamate pesticide spraying was longer than a month before enrollment. Therefore, the metabolites could not be captured. This could probably be a cause for our negative correlation.

Our study reported that wearing a mask while spraying pesticides was associated with lower dimethyl metabolites. This result is consistent with several studies that have indicated a correlation between PPE utilization and lower DAP levels $[37,62]$. In addition, a positive correlation was found between diethyl metabolite level and the behavior of pesticide sprayers, such as reading pesticide labels before mixing and washing hands after mixing pesticides. This finding corresponds with a previous study that pointed out the association between the working practices of farmers and pesticide exposure levels [63].

There are several limitations of this study. Due to the complicated data collection process, participants were not randomly selected. Therefore, healthy people tended to be recruited because of awareness about their health. Our sample size was smaller than expected because of the difficulty of contacting farmworkers who lived in mountain villages. Another point to note is that the ability to represent chronic OP exposure and variation of urinary DAP metabolites over time might have been limited due to single morning urine collection. As our DAP analytical method had lower sensitivity compared to other studies, detectable metabolites in our study might not represent the real values. In addition, farmworkers might overreport PPE utilization and appropriate work practices as they were not observed while working.

\section{Conclusions}

This study did not observe an association between OP pesticide exposure and insulin resistance in pesticide sprayers and nonfarmworkers. However, the results are inconclusive due to limitation in detecting chronic exposure from single urinary DAP metabolites. In addition, the general population had similar OP pesticide exposure level, which was associated with consumption of fruit and vegetable contaminated with OP. The results therefore need further longitudinal studies with adequate sample size and multiple urine samples. Although there was no evidence of a correlation between measurable DAP metabolites and adverse health effect, the DAP levels reflect high exposure in our nonfarmworker group. Measures to control pesticide exposure should therefore be taken.

Author Contributions: Conceptualization, M.S. and R.G.L.; methodology, M.S., R.G.L., and S.S.; software, M.S. and R.S.; validation, M.S. and R.S.; formal analysis, S.H.; investigation, M.S.; resources, M.S. and P.K.; data curation, M.S. and R.S.; writing—original draft preparation, M.S.; writing-review and editing, R.G.L. and S.W.; visualization, M.S.; supervision, R.G.L. and S.S.; project administration, M.S.; funding acquisition, S.W. and P.K. All authors have read and agreed to the published version of the manuscript.

Funding: This research was funded by the Fogarty International Center of the National Institutes of Health under Award Number U2RTW010088. The content is solely the responsibility of the authors and does not necessarily represent the official views of the National Institutes of Health.

Acknowledgments: This research study was supported by Chiang Mai University, Icahn School of Medicine at Mount Sinai, and Research Institute for Health Science, Chiang Mai University. We are grateful for the assistance of Pong Yaeng Health Promoting Hospital, Suthep Subdistrict Municipality, village health volunteers, and community leaders. We would like to thank all participants for their cooperation and contribution to this study.

Conflicts of Interest: The authors declare no conflict of interest.

\section{References}

1. World Health Organization. The Top 10 Cause of Death 2018. 2018. Available online: https://www.who.int/ news-room/fact-sheets/detail/the-top-10-causes-of-death (accessed on 20 May 2020).

2. International Diabetes Federation. IDF Diabetes Atlas, 9th ed.; International Diabetes Federation: Brussels, Belgium, 2019; pp. 34-35. 
3. Division of Non Communicable Diseases. Number and Rate of Death from Non-Communicable Diseases 2016-2018. 2019. Available online: http://www.thaincd.com/2016/mission/documents-detail.php?id=13653\& tid=32\&gid=1-020 (accessed on 20 May 2020).

4. Guo, S. Insulin signaling, resistance, and metabolic syndrome: Insights from mouse models into disease mechanisms. J. Endocrinol. 2014, 220, T1-T23. [CrossRef] [PubMed]

5. Zaccardi, F.; Webb, D.R.; Yates, T.; Davies, M.J. Pathophysiology of type 1 and type 2 diabetes mellitus: A 90-year perspective. Postgrad. Med. J. 2016, 92, 63-69. [CrossRef] [PubMed]

6. Adeva-Andany, M.M.; Martínez-Rodríguez, J.; González-Lucán, M.; Fernández-Fernánde, C.; Castro-Quintela, E. Insulin resistance is a cardiovascular risk factor in humans. Diabetes Metab. Syndr. 2019, 13, 1449-1455. [CrossRef] [PubMed]

7. Ormazabal, V.; Nair, S.; Elfeky, O.; Aguayo, C.; Salomon, C.; Zuñiga, F.A. Association between insulin resistance and the development of cardiovascular disease. Cardiovasc. Diabetol. 2018, 27, 122. [CrossRef] [PubMed]

8. Ma, L.; Wang, J.; Li, Y. Insulin resistance and cognitive dysfunction. Clin. Chim. Acta 2015, 444, 18-23. [CrossRef] [PubMed]

9. Mu, N.; Zhu, Y.; Wang, Y.; Zhang, H.; Xue, F. Insulin resistance: A significant risk factor of endometrial cancer. Gynecol. Oncol. 2012, 125, 751-757. [CrossRef]

10. Di Sebastiano, K.M.; Pinthus, J.H.; Duivenvoorden, W.C.; Mourtzakis, M. Glucose impairments and insulin resistance in prostate cancer: The role of obesity, nutrition and exercise. Obes. Rev. 2018, 19, 1008-1016. [CrossRef] [PubMed]

11. Cirillo, F.; Catellani, C.; Sartori, C.; Lazzeroni, P.; Amarri, S.; Street, M.E. Obesity, Insulin Resistance, and Colorectal Cancer: Could miRNA Dysregulation Play A Role? Int. J. Mol. Sci. 2019, 20, 2922. [CrossRef] [PubMed]

12. Brown, A.E.; Walker, M. Genetics of Insulin Resistance and the Metabolic Syndrome. Curr. Cardiol. Rep. 2016, 18, 75. [CrossRef] [PubMed]

13. Sell, H.; Habich, C.; Eckel, J. Adaptive immunity in obesity and insulin resistance. Nat. Rev. Endocrinol. 2012, 8, 709-716. [CrossRef] [PubMed]

14. Ye, J. Mechanisms of insulin resistance in obesity. Front. Med. 2013, 7, 14-24. [CrossRef]

15. Gratas-Delamarche, A.; Derbré, F.; Vincent, S.; Cillard, J. Physical inactivity, insulin resistance, and the oxidative-inflammatory loop. Free Radic Res. 2013, 48, 93-108. [CrossRef]

16. Black, M.H.; Watanabe, R.M.; Trigo, E.; Takayanagi, M.; Lawrence, J.M.; Buchanan, T.A.; Xiang, A.H. High-fat diet is associated with obesity-mediated insulin resistance and beta-cell dysfunction in Mexican Americans. J. Nutr. 2013, 143, 479-485. [CrossRef]

17. Boden, G.; Homko, C.; Barrero, C.A.; Stein, T.P.; Chen, X.; Cheung, P.; Fecchio, C.; Merail, S. Excessive caloric intake acutely causes oxidative stress, GLUT4 carbonylation, and insulin resistance in healthy men. Sci. Transl. Med. 2015, 7, 1-19. [CrossRef] [PubMed]

18. Śliwińska-Mossoń, M.; Milnerowicz, H. The impact of smoking on the development of diabetes and its complications. Diab. Vasc. Dis. Res. 2017, 14, 265-276. [CrossRef] [PubMed]

19. Liang, Y.; Zhan, J.; Liu, D.; Luo, M.; Han, J.; Liu, X.; Liu, C.; Cheng, Z.; Zhou, Z.; Wang, P. Organophosphorus pesticide chlorpyrifos intake promotes obesity and insulin resistance through impacting gut and gut microbiota. Microbiome 2019, 7, 19. [CrossRef] [PubMed]

20. Zhang, Y.; Ren, M.; Li, J.; Wei, Q.; Ren, Z.; Lv, J.; Niu, F.; Ren, S. Does omethoate have the potential to cause insulin resistance? Environ. Toxicol. Pharmacol. 2014, 37, 284-290. [CrossRef]

21. Pournourmohammadi, S.; Ostad, S.N.; Azizi, E.; Ghahremani, M.H.; Farzami, B.; Minaie, B.; Larijani, B.; Abdollahi, M. Induction of insulin resistance by malathion: Evidence for disrupted islets cells metabolism and mitochondrial dysfunction. Pestic. Biochem. Physiol. 2007, 88, 346-352. [CrossRef]

22. Mostafalou, S.; Eghbal, M.A.; Nili-Ahmadabadi, A.; Baeeri, M.; Abdollahi, M. Biochemical evidence on the potential role of organophosphates in hepatic glucose metabolism toward insulin resistance through inflammatory signaling and free radical pathways. Toxicol. Ind. Health 2012, 28, 840-851. [CrossRef]

23. Riwthong, S.; Schreinemachers, P.; Grovermann, C.; Berger, T. Agricultural commercialization: Risk perceptions, risk management and the role of pesticides in Thailand. Kasetsart. J. Soc. Sci. 2017, 38, 264-272. [CrossRef] 
24. Mohammad, N.; Abidin, E.Z.; How, V.; Praveena, S.M.; Hashim, Z. Pesticide management approach towards protecting the safety and health of farmers in Southeast Asia. Rev. Environ. Health 2018, 33, 123-134.

25. Survey Contact of Agricultural Regulatory Office. Report of Top 10 Import Hazardous Substances 2019. 2019. Available online: http://www.doa.go.th/ard/wp-content/uploads/2020/02/HASTAT62_03.pdf (accessed on 30 May 2020).

26. Environmental Research and Training Center. The Study of Method for Decreasing Chemical Use in Agriculture by Participatory Research: Case Study in Mae Tang District, Chiang Mai; Environmental Research and Training Center: Pathum Thani, Thailand, 2014; pp. 90-106.

27. Bureau of Non Communicable Diseases. Number of New Hypertensive and Diabetic Patients of Fiscal Year 2017. 2017. Available online: http://www.thaincd.com/2016/mission/documents-detail.php?id=12621\& .tid=32\&gid=1-020 (accessed on 22 January 2020).

28. Starling, A.P.; Umbach, D.M.; Kamel, F.; Long, S.; Sandler, D.P.; Hoppin, J.A. Pesticide use and incident diabetes among wives of farmers in the Agricultural Health Study. Occup. Environ. Med. 2014, 71, 629-635. [CrossRef] [PubMed]

29. Jamal, F.; Haque, Q.S.; Singh, S. Interrelation of Glycemic Status and Neuropsychiatric Disturbances in Farmers with Organophosphorus Pesticide Toxicity. Open Biochem. J. 2016, 10, 27-34. [CrossRef]

30. Juntarawijit, C.; Juntarawijit, Y. Association between diabetes and pesticides: A case-control study among Thai farmers. Environ. Health Prev. Med. 2018, 23, 3. [CrossRef] [PubMed]

31. Raafat, N.; Abass, M.A.; Salem, H.M. Malathion exposure and insulin resistance among a group of farmers in Al-Sharkia governorate. Clin. Biochem. 2012, 45, 1591-1595. [CrossRef]

32. Prapamontol, T.; Sutan, K.; Laoyang, S.; Hongsibsong, S.; Lee, G.; Yano, Y.; Hunter, R.E.; Ryan, P.B.; Barr, D.B.; Panuwet, P. Cross validation of gas chromatography-flame photometric detection and gas chromatography-mass spectrometry methods for measuring dialkylphosphate metabolites of organophosphate pesticides in human urine. Int. J. Hyg. Environ. Health 2014, 217, 554-566. [CrossRef]

33. Hornung, R.W.; Reed, L.D. Estimation of average concentration in the presence of nondetectable values. Appl. Occup. Environ. Hyg. 1990, 5, 46-51. [CrossRef]

34. Matthews, D.R.; Hosker, J.P.; Rudenski, A.S.; Naylor, B.A.; Treacher, D.F.; Turner, R.C. Homeostasis model assessment: Insulin resistance and $\beta$-cell function from fasting plasma glucose and insulin concentrations in man. Diabetologia 1985, 28, 412-419. [CrossRef]

35. Friedewald, W.T.; Levy, R.I.; Fredrickson, D.S. Estimation of the concentration of low-density lipoprotein cholesterol in plasma, without use of the preparative ultracentrifuge. Clin. Chem. 1972, 18, 499-502. [CrossRef]

36. van den Dries, M.A.; Pronk, A.; Guxens, M.; Spaan, S.; Voortman, T.; Jaddoe, V.W.; Jusko, T.A.; Longnecker, M.P.; Tiemeier, H. Determinants of organophosphate pesticide exposure in pregnant women: A population-based cohort study in the Netherlands. Int. J. Hyg. Environ. Health 2018, 221, 489-501. [CrossRef]

37. Koureas, M.; Tsakalof, A.; Tzatzarakis, M.; Vakonaki, E.; Tsatsakis, A.; Hadjichristodoulou, C. Biomonitoring of organophosphate exposure of pesticide sprayers and comparison of exposure levels with other population groups in Thessaly (Greece). Occup. Environ. Med. 2014, 71, 126-133. [CrossRef]

38. Taneepanichskul, N.; Norkaew, S.; Siriwong, W.; Siripattanakul-Ratpukdi, S.; Pérez, H.L.; Robson, M.G. Organophosphate pesticide exposure and dialkyl phosphate urinary metabolites among chili farmers in Northeastern Thailand. Rocz. Panstw. Zakł. Hig. 2014, 65, 291-299.

39. Bravo, R.; Caltabiano, L.M.; Weerasekera, G.; Whitehead, R.D.; Fernandez, C.; Needham, L.L.; Bradman, A.; Barr, D.B. Measurement of dialkyl phosphate metabolites of organophosphorus pesticides in human urine using lyophilization with gas chromatography-tandem mass spectrometry and isotope dilution quantification. J. Expo. Anal. Environ. Epidemiol. 2004, 14, 249-259. [CrossRef] [PubMed]

40. Berman, T.; Goldsmith, R.; Goen, T.; Spungen, J.; Novack, L.; Levine, H.; Amitai, Y.; Shohat, T.; Grotto, I. Urinary concentrations of organophosphate pesticide metabolites in adults in Israel: Demographic and dietary predictors. Environ. Int. 2013, 60, 183-189. [CrossRef]

41. Bradman, A.; Castorina, R.; Barr, D.B.; Chevrier, J.; Harnly, M.E.; Eisen, E.A.; McKone, T.E.; Harley, K.; Holland, N.; Eskenazi, B. Determinants of organophosphorus pesticide urinary metabolite levels in young children living in an agricultural community. Int. J. Environ. Res. Public Health 2011, 8, 1061-1083. [CrossRef] [PubMed] 
42. Curl, C.L.; Beresford, S.A.; Fenske, R.A.; Fitzpatrick, A.L.; Lu, C.; Nettleton, J.A.; Kaufman, J.D. Estimating pesticide exposure from dietary intake and organic food choices: The Multi-Ethnic Study of Atherosclerosis (MESA). Environ. Health Perspect 2015, 123, 475-483. [CrossRef]

43. Oates, L.; Cohen, M.; Braun, L.; Chembri, A.; Taskova, R. Reduction in urinary organophosphate pesticide metabolites in adults after a week-long organic diet. Environ. Res. 2014, 132, 105-111. [CrossRef] [PubMed]

44. Silipunyo, T.; Hongsibsong, S.; Phalaraksh, C.; Laoyang, S.; Kerdnoi, T.; Patarasiriwong, V.; Prapamontol, T. Determination of organophosphate pesticides residues in fruits, vegetables and health risk assessment among consumers in Chiang Mai Province, Northern Thailand. Res. J. Environ. Toxicol. 2017, 11, $20-27$.

45. Ranjbar, M.; Rotondi, M.A.; Ardern, C.I.; Kuk, J.L. The Influence of Urinary Concentrations of Organophosphate Metabolites on the Relationship between BMI and Cardiometabolic Health Risk. J. Obes. 2015, 2015, 687914. [CrossRef]

46. Cheng, Y.H.; Tsao, Y.C.; Tzeng, I.S.; Chuang, H.H.; Li, W.C.; Tung, T.H.; Chen, J.Y. Body mass index and waist circumference are better predictors of insulin resistance than total body fat percentage in middle-aged and elderly Taiwanese. Medicine 2017, 96, e8126. [CrossRef]

47. Chung, J.O.; Cho, D.H.; Chung, D.J.; Chung, M.Y. Associations among body mass index, insulin resistance, and pancreatic $\beta$-cell function in Korean patients with new-onset type 2 diabetes. Korean J. Intern Med. 2012, 1, 66-71. [CrossRef]

48. Acker, C.I.; Nogueira, C.W. Chlorpyrifos acute exposure induces hyperglycemia and hyperlipidemia in rats. Chemosphere 2012, 89, 602-608. [CrossRef] [PubMed]

49. Nagaraju, R.; Joshi, A.K.; Rajini, P.S. Organophosphorus insecticide, monocrotophos, possesses the propensity to induce insulin resistance in rats on chronic exposure. J. Diabetes 2014, 7, 47-59. [CrossRef] [PubMed]

50. Dash, D.K.; Choudhury, A.K.; Singh, M.; Mangaraj, S.; Mohanty, B.K.; Baliarsinha, A.K. Effect of parental history of diabetes on markers of inflammation, insulin resistance and atherosclerosis in first degree relatives of patients with type 2 diabetes mellitus. Diabetes Met. Synd. 2018, 12, 285-289. [CrossRef]

51. Aekplakorn, W.; Chariyalertsak, S.; Kessomboon, P.; Assanangkornchai, S.; Taneepanichskul, S.; Putwatana, P. Prevalence of Diabetes and Relationship with Socioeconomic Status in the Thai Population: National Health Examination Survey, 2004-2014. J. Diabetes Res. 2018, 2018, 1654530. [CrossRef]

52. Apidechkul, T.; Laingoen, O.; Suwannaporn, S. Inequity in accessing health care service in Thailand in 2015: A case study of the hill tribe people in Mae Fah Luang district, Chiang Rai, Thailand. J. Health Res. 2016, 30, 67-71.

53. Apidechkul, T. Prevalence and factors associated with type 2 diabetes mellitus and hypertension among the hill tribe elderly populations in northern Thailand. BMC Public Health 2018, 18, 694. [CrossRef]

54. Wu, R.R.; Myers, R.A.; Hauser, E.R.; Vorderstrasse, A.; Cho, A.; Ginsburg, G.S.; Orlando, L.A. Impact of genetic testing and family health history based risk counseling on behavior change and cognitive precursors for type 2 diabetes. J. Genet Couns. 2017, 26, 133-140. [CrossRef] [PubMed]

55. Choi, J.; Choi, J.Y.; Lee, S.A.; Lee, K.M.; Shin, A.; Oh, J.; Park, J.; Song, M.; Yang, J.J.; Lee, J.K.; et al. Association between family history of diabetes and clusters of adherence to healthy behaviors: Cross-sectional results from the Health Examinees-Gem (HEXA-G) study. BMJ Open 2019, 9, e025477. [CrossRef] [PubMed]

56. Kissel, J.C.; Curl, C.L.; Kedan, G.; Lu, C.; Griffith, W.; Barr, D.B.; Needham, L.L.; Fenske, R.A. Comparison of organophosphorus pesticide metabolite levels in single and multiple daily urine samples collected from preschool children in Washington State. J. Expo. Sci. Environ. Epidemiol. 2004, 15, 164-171. [CrossRef]

57. Bradman, A.; Kogut, K.; Eisen, E.A.; Jewell, N.P.; Quiros-Alcala, L.; Castorina, R.; Chevrier, J.; Holland, N.T.; Barr, D.B.; Kavanagh-Baird, G.; et al. Variability of organophosphorous pesticide metabolite levels in spot and 24-hr urine samples collected from young children during 1 week. Environ. Health Perspect. 2013, 121, 118-124. [CrossRef]

58. Spaan, S.; Pronk, A.; Koch, H.M.; Jusko, T.A.; Jaddoe, V.W.; Shaw, P.A.; Tiemeier, H.M.; Hofman, A.; Pierik, F.H.; Longnecker, M.P. Reliability of concentrations of organophosphate pesticide metabolites in serial urine specimens from pregnancy in the Generation R Study. J. Expo. Sci. Environ. Epidemiol. 2015, 25, 286-294. [CrossRef]

59. Barr, D.B.; Wong, L.Y.; Bravo, R.; Weerasekera, G.; Odetokun, M.; Restrepo, P.; Kim, D.G.; Fernandez, C.; Perez, J.; Gallegos, M.; et al. Urinary concentrations of dialkylphosphate metabolites of organophosphorus pesticides: National Health and Nutrition Examination Survey 1999-2004. Int. J. Environ. Res. Public Health 2011, 8, 3063-3098. [CrossRef] 
60. Suratman, S.; Edwards, J.W.; Babina, K. Organophosphate pesticides exposure among farmworkers: Pathways and risk of adverse health effects. Rev. Environ. Health 2015, 30, 65-79. [PubMed]

61. Karami-Mohajeri, S.; Abdollahi, M. Toxic influence of organophosphate, carbamate, and organochlorine pesticides on cellular metabolism of lipids, proteins, and carbohydrates: A systematic review. Hum. Exp. Toxicol. 2011, 30, 1119-1140. [CrossRef]

62. Aguilar-Garduño, C.; Blanco-Muñoz, J.; Antonio, K.R.; Escamilla-Nuñez, C.; Juárez-Pérez, C.A.; Schilmann, A.; Cebrian, M.E.; Lacasaña, M. Occupational predictors of urinary dialkyl phosphate concentrations in Mexican flower growers. Int. J. Occup. Environ. Health 2017, 23, 151-159. [CrossRef]

63. Zhang, X.; Zhao, W.; Jing, R.; Wheeler, K.; Smith, G.A.; Stallones, L.; Xiang, H. Work-related pesticide poisoning among farmers in two villages of Southern China: A cross-sectional survey. BMC Public Health 2011, 11, 429. [CrossRef] [PubMed]

Publisher's Note: MDPI stays neutral with regard to jurisdictional claims in published maps and institutional affiliations.

(C) 2020 by the authors. Licensee MDPI, Basel, Switzerland. This article is an open access article distributed under the terms and conditions of the Creative Commons Attribution (CC BY) license (http://creativecommons.org/licenses/by/4.0/). 